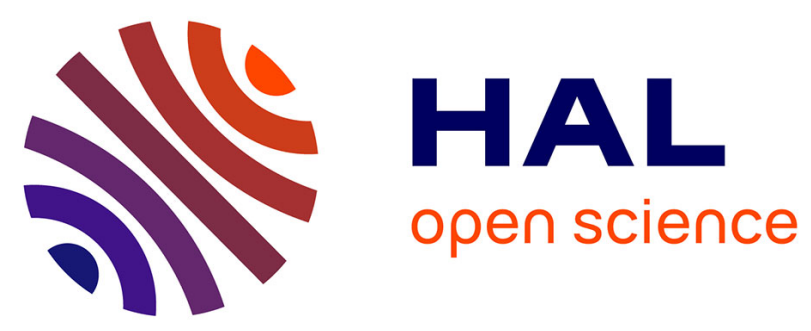

\title{
Parametric study of a moderate pressure nanosecond discharge to reduce detonation cell width
}

\author{
Mhedine Ali Cherif, Laurent Catoire, Pierre Vidal, Alain Claverie, Svetlana M
}

Starikovskaia

\section{- To cite this version:}

Mhedine Ali Cherif, Laurent Catoire, Pierre Vidal, Alain Claverie, Svetlana M Starikovskaia. Parametric study of a moderate pressure nanosecond discharge to reduce detonation cell width. AIAA Scitech 2021 Forum Session: Plasma-Assisted Combustion III, Jan 2021, Nashville, TN, United States. 10.2514/6.2021-1789 . hal-03428345

\section{HAL Id: hal-03428345 \\ https://hal.science/hal-03428345}

Submitted on 16 Nov 2021

HAL is a multi-disciplinary open access archive for the deposit and dissemination of scientific research documents, whether they are published or not. The documents may come from teaching and research institutions in France or abroad, or from public or private research centers.
L'archive ouverte pluridisciplinaire HAL, est destinée au dépôt et à la diffusion de documents scientifiques de niveau recherche, publiés ou non, émanant des établissements d'enseignement et de recherche français ou étrangers, des laboratoires publics ou privés. 


\title{
Parametric study of a moderate pressure nanosecond discharge to reduce detonation cell width
}

\author{
Mhedine Ali Cherif* \\ Laboratoire de Physique des Plasmas, CNRS, Sorbonne Université, Université Paris-Saclay, École Polytechnique, \\ Institut Polytechnique de Paris, Palaiseau, 91128, France \\ Laurent Catoire ${ }^{\dagger}$ \\ Unité Chimie et Procédés, ENSTA ParisTech, University Paris-Saclay, Palaiseau, 91128, France \\ Pierre Vidal ${ }^{\ddagger}$, Alain Claverie ${ }^{\S}$ \\ Institut Pprime, UPR 3346 CNRS, ENSMA, 86034 Chasseneuil-du-Poitou, France \\ Svetlana M. Starikovskaia ${ }^{\text {I }}$ \\ Laboratoire de Physique des Plasmas, CNRS, Sorbonne Université, Université Paris-Saclay, École Polytechnique, \\ Institut Polytechnique de Paris, Palaiseau, 91128, France
}

\begin{abstract}
In a former work, the effect of a volumetric nanosecond discharge at decreasing the detonation cell size was demonstrated experimentally. The experiments were performed under non-optimal conditions for plasma homogeneity. The present work is a paremetric study that aims at optimizing these experimental conditions. An electrode system was installed in a tube to produce a double-pulse discharge with high deposited energy ahead of the detonation front. The amplitude of the high-voltage pulses, the gas mixture and pressure were optimized so that the plasma filled the entire interelectrode space. The analysis of the detonation cell size with and without plasma generation was performed via the sooted-plate technique. Production of atoms and radicals in the discharge triggered combustion chemistry and decreased the ignition delay time. At these optimal conditions, the detonation cell size was thus reduced by a factor of 2 , while passing through the region of the discharge.
\end{abstract}

\section{Introduction}

Detonation offers high pressure and temperature environement as well as short characteristic times and lengths [1]. Its high surface power is usefull to technological applications such as propulsion. However, the understanding and control of the phenomenon is still to establish. Increasing the efficiency of a detonation without increasing the initial pressure (for safety requirements) remains a challenge. Non-equilibrium plasma is well known to enhance the reactivity of a medium by predissociation without increasing initial pressure. [2].

One way to define the detonability of a gas mixture is its capacity to propagate in a channel. Experiments show that the detonation front is unstable and the chemical reaction zone has a 3D cellular structure. A semi-empirical link between detonability and the mean width of the detonation cells has been commonly used [1]. The activation energy of a gas mixture is an important component for characterizing the detonation cellular structure.

The mean width of the detonation cells is therefore a convenient critetion for measuring detonability. The detonation front adapts rapidly to changes in compsition of the fresh gas. A reduction of cell mean width was observed in the case of gradiants of equivalence ratio parallel to the detonation front propagation [3]. The present work aims at observing changes of the mean width of the detonation cell by direct application of a nanosecond plasma ahead of the detonation front.

Plasma-assisted combustion is a promising technology, and recent progress were made in the field of non-thermal and thermal enhancement effects, kinetic pathways of atomic $\mathrm{O}$ production and kinetics of sub-explosion limit ignition

\footnotetext{
*Graduate student, Laboratory of Plasma Physics, CNRS, Ecole Polytechnique.

†Professor, ENSTA, CNRS, Ecole Polytechnique.

†Sernior researcher, CNRS, Institut Pprime.

$\S$ Research engineer, CNRS, Institut Pprime.

"ISenior researcher, CNRS, Ecole Polytechnique.
} 
[4]. Nanosecond plasmas provide instantaneous change of the initial composition of the mixture at the time-scale of the detonation reaction zone. Due to the non-equilibrium nature of the discharge, the energy is distributed mostly to increase the electron temperature, thereby, enhancing the chemical reactivity by modifying of the EEDF [2, 4, 5].

A reduction of ignition delay time was observed in shock-tube experiments up to 4 orders of magnitude for methane-based mixtures in [6]. Deflagration-to-detonation transition assisted by plasma was widely investigated both experimentally and numerically [7- -9$]$.

Recent studies show the effect of oxygen dissociation on the cell size and therfore on the detonability. The study of Crane et al. [10] highlights the effects of the premixing of ozone to a $\mathrm{H}_{2}: \mathrm{O}_{2}$ mixture. They observed a reduction of the cell size up to $70 \%$ with the addiction of $3000 \mathrm{PPM}$ of ozone at pressures from $10 \mathrm{kPa}$ up to $30 \mathrm{kPa}$. The calculation of Tropina et Al. [9] show a reduction of the cell size up to a factor of 2 by local injection of $\mathrm{O}$ atoms to enhance the DDT process. The local injection of radical was found to be more efficient than a classical joule heating source. Finally the experimental proof of the reduction of the cell size by direct application of a plasma to the fresh gas was made by Ali Cherif et al. [11]. The present work aimes at optimizing the experimental conditions of the study to maximize the effect of the discharge on the detonability.

\section{Experimental Setup}

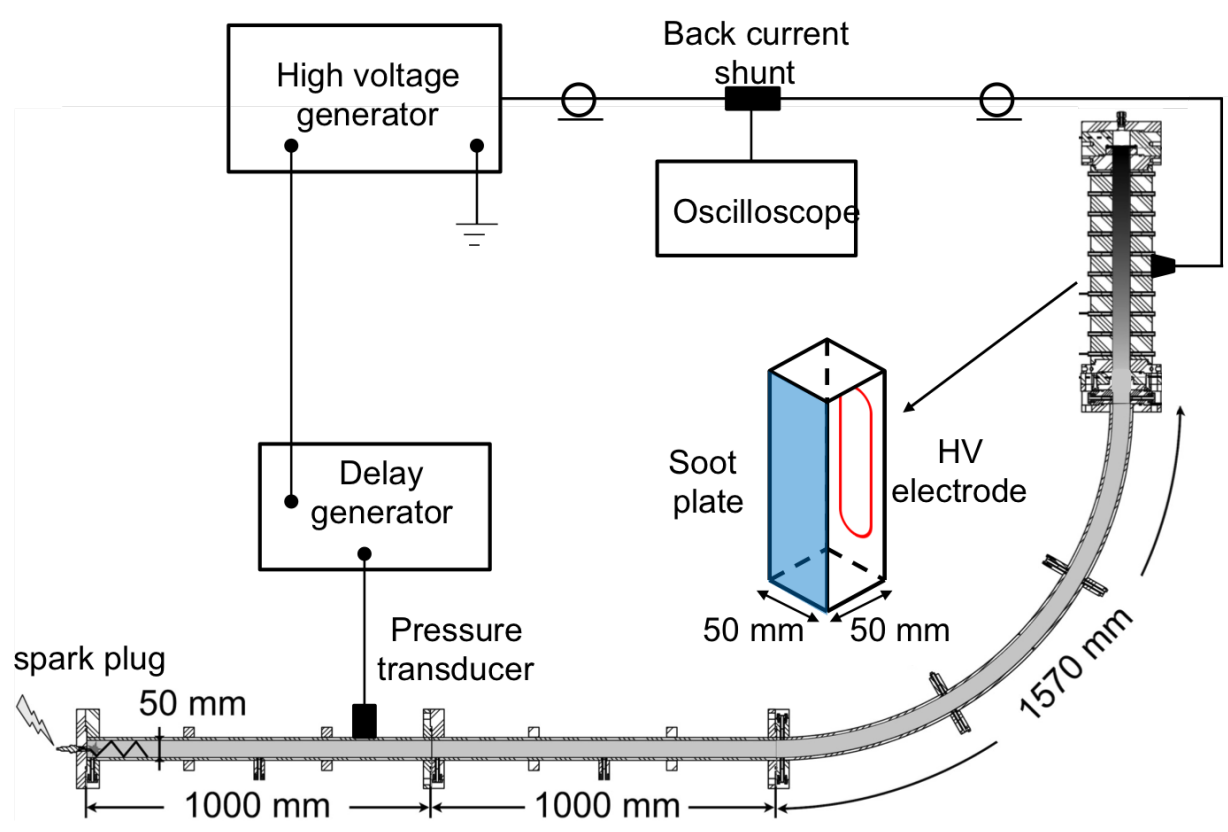

Fig. 1 Schematic of the experimental setup showing the detonation tube and the diagnostic chamber. The locations of the $\mathrm{HV}$ electrode in the diagnostic chamber are shown in red and blue in the insert.

Figure 1 shows a schematic of the experimental setup. The detonation tube is composed of a a 665 -mm long, $50 \times 50-\mathrm{mm}^{2}$ cross-section vertical diagnostic chamber and a $3570-\mathrm{mm}$ long, $50 \times 50-\mathrm{mm}^{2}$ square cross-section detonation channel. The detonation is generated in the channel by means of a DDT process initiated by a spark plug and accelerated by a Shchelkin spiral(Fig 11). In the following experiments the detonation wave enters the chamber at Chapman-Jouguet velocity. The squared cross-section diagnostic chamber consist of four replaceable flanges, and is shown schematically in the insert in Fig. 1. A brass high-voltage electrode, $25 \times 360 \mathrm{~mm}^{2}$, is installed in a dielectric (PEEK) plate mounted in a stainless steel flange. A sooted plate $\left(1 \mathrm{~mm}\right.$ thick stainless steel plate $50 \times 550 \mathrm{~mm}^{2}$ covered with a thin carbon layer) is mounted on the stainless steel flange opposite to the high-voltage electrode and serves as the grounded electrode. The high-voltage and the grounded electrodes are indicated by red and blue colours, respectively. The other two flanges of the chamber are 500-mm long quartz optical windows.

A set of ten Kistler 603B piezoelectric pressure transducers (response time $1 \mu \mathrm{s}$, natural frequency $300 \mathrm{kHz}$ ) together with Kistler 5018A electrostatic charge amplifiers (bandwidth $200 \mathrm{kHz}$ ) was used to measure the wave longitudinal mean velocity $D$. The first transducer that detected a detonation event (Fig 11) provided a synchronization signal for 
triggering the high-voltage generator and the ICCD camera.

A high-voltage generator FPG 25-001NM2C2 (FID GmbH) was designed to deliver a burst of three pulses of negative polarity, 10-50 kV amplitude, to the electrode with 3-4-ns rise time and 25-ns duration at FWHM, with a possibility to change independently the amplitude of each pulse and an adjustable 200-2000-ns delay between them. The high-voltage signal was transmitted through a 30-m long coaxial electrical RG213 cable to the high-voltage electrode. The waveforms of the high-voltage pulses and the deposited energy were measured by means of a custom-made, calibrated back current shunt (BCS) mounted in the grounded shield in the middle of the cable. The BCS was connected to a LeCroy WaveRunner 4Xi-A 600-MHz oscilloscope. The details of the BCS technique have been described elsewhere [12].

The optical emission from the discharge and optical emission produced by the detonation wave was monitored by an ICCD PI-MAX2 camera (Princeton Instruments) with a spectral sensitivity range of 200-800 nm.

The energy deposition measurement and the ICCD images were used to establish the optimal parameters for the experiments. The classical sooted-plate technique was used to compare the structure and the size of the detonation cells obtained without and with plasma action. The sooted plate was changed after each experiment.

\section{Results and Discussion}
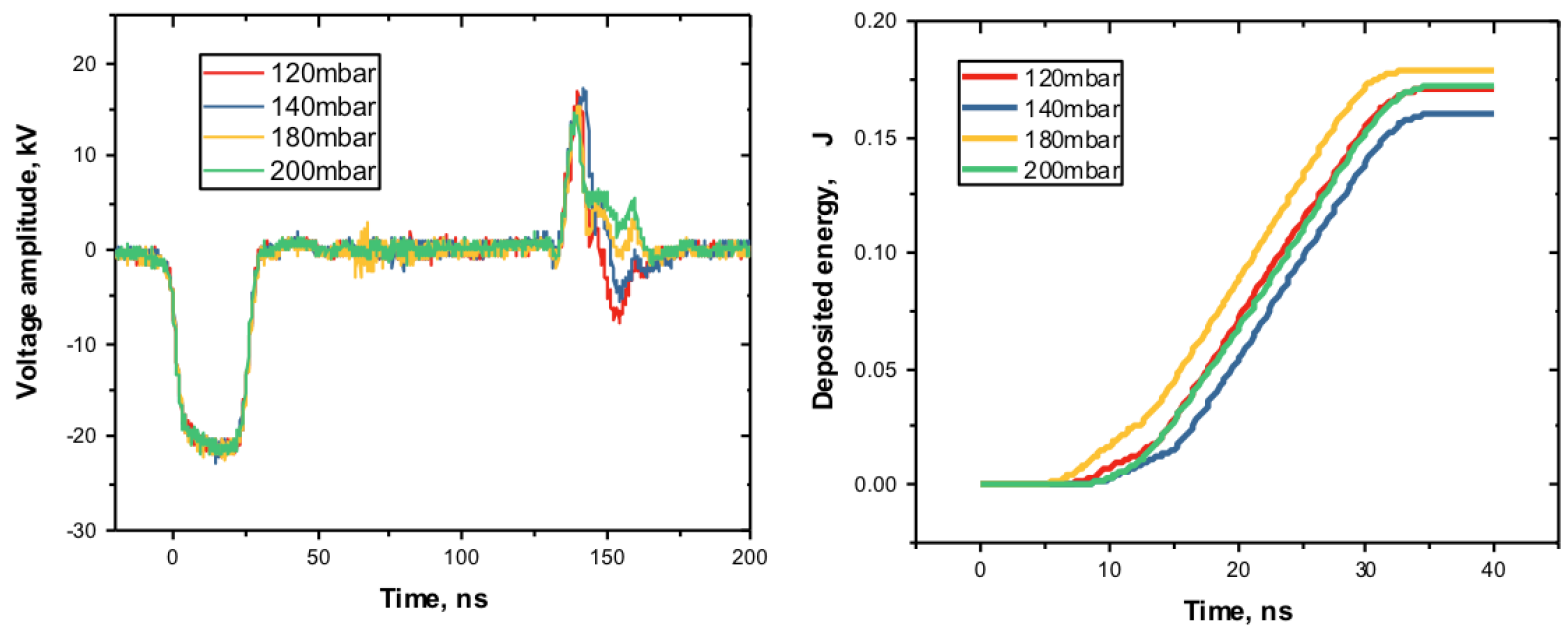

Fig. 2 Waveform of the first pulse (left) and measured energy deposition (right) for several initial pressures in $\mathrm{CH}_{4}: \mathrm{O}_{2}: \mathrm{Ar}: \mathrm{H}_{2}$ mixture at $298 \mathrm{~K}$

The experiments were initially carried out in a $\mathrm{CH}_{4}: \mathrm{O}_{2}$ :Ar mixture (1:2:2) at moderate pressures and ambient initial temperature (293-298 K) [11]. The detonation cell size is considered as being, in particular, strongly dependent on the activation energy of the mixture, and thus the ignition delay time. The selection of the main fuel in the mixture was thus dictated by the fact that methane is the alkane most sensitive to plasma action, demonstrating the strongest decrease of ignition delay time [2].

The very low detonability of methane motivates the addition of hydrogen in the mixture to facilitate to reading of the soot-plates. Hydrogen-based mixtures produce cell patterns that are more uniform and thus easier to read. A set of experiments was carried out to study the discharge development in stoichiometric $\mathrm{CH}_{4}: \mathrm{O}_{2}: \mathrm{Ar}_{2} \mathrm{H}_{2}$ mixtures with different percentage of hydrogen (10 and 20\%) at ambient temperature and initial pressures ranging from 50 to 200 mbar. Stable detonation and a volumetric plasma were the key criteria to establish the optimal parameters.

Figures 2 and 3 present the waveform of the first pulse (left) and the energy deposition (right) for different pressures and mixtures respectively. The working pressures were selected according to the obtained data- the initial pressures 120 , 180 and 200 mbar showed the highest energy deposition in the 50-200 mbar range with a minimum at $140 \mathrm{mbar}$. The same study was repeated for different percentages of hydrogen in the mixture. The pressures selected were 120 and 180 mbar. For the previous conditions, a higher hydrogen concentration led to higher energy deposition in particular at higher pressure but it also increased dramatically the risk of ignition of the mixture by filamentary discharge before the detonation wave passage. The stoichimetric $\mathrm{O}_{2}: \mathrm{CH}_{4}: \mathrm{Ar}_{2} \mathrm{H}_{2}$ (7:3:8:2) was thus selected has the working mixture for the rest of the experiments. 

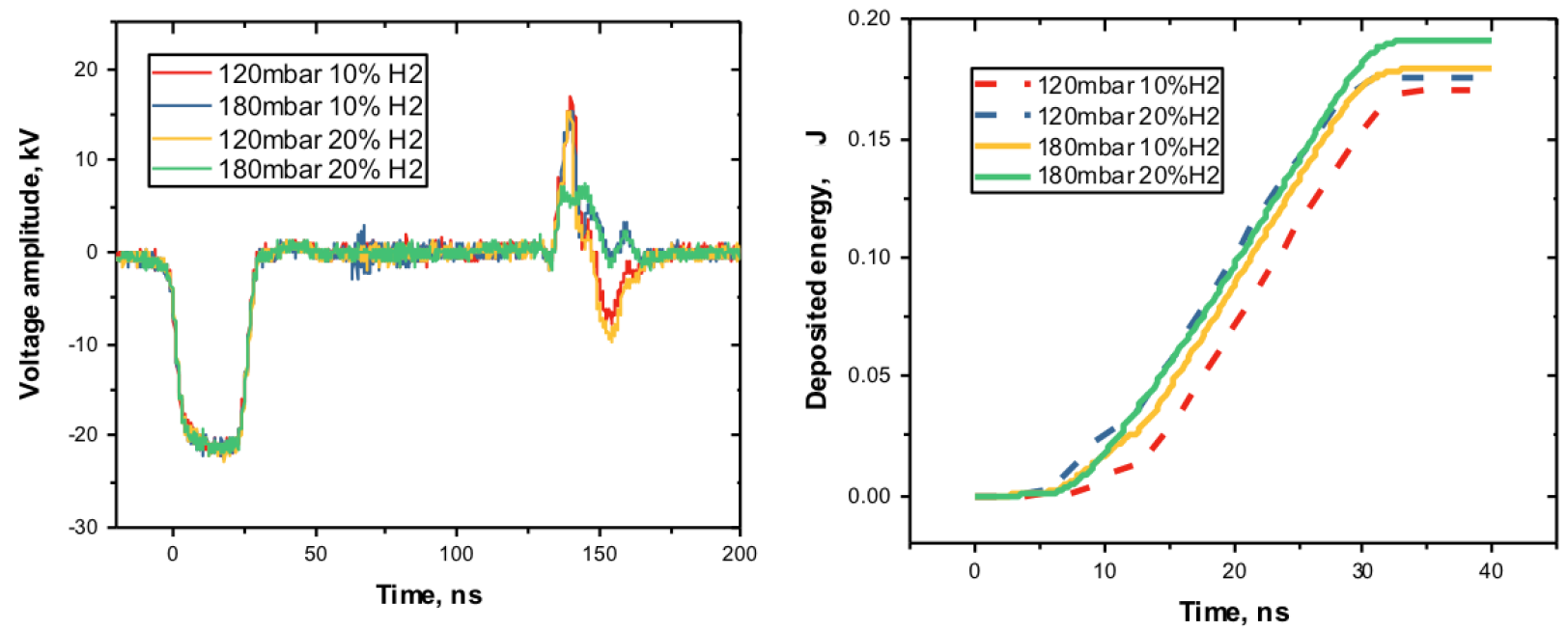

Fig. 3 Waveform of the first pulse (left) and measured energy deposition (right) in $\mathrm{CH}_{4}: \mathrm{O}_{2}: \mathrm{Ar}: \mathrm{H}_{2}$ mixtures containing 10 and $20 \%$ Hydrogen and initial pressures 120 and 180 mbar at $298 \mathrm{~K}$

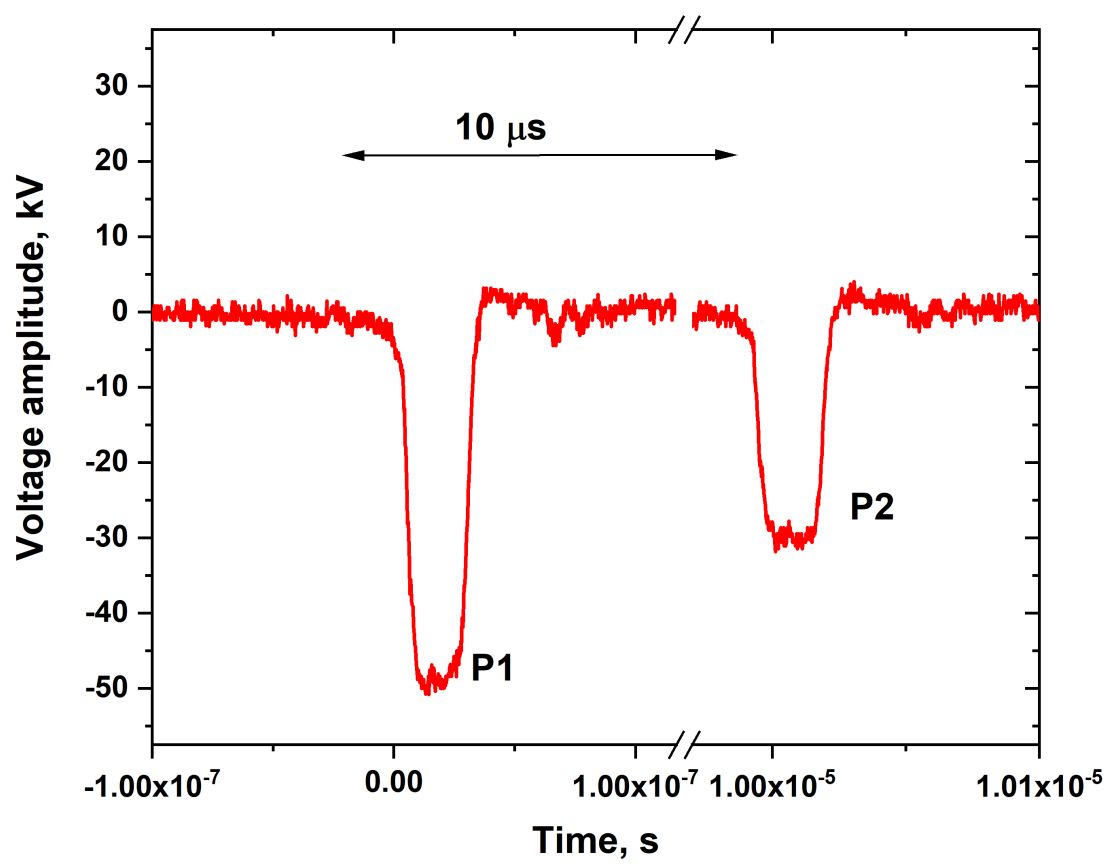

Fig. 4 Voltage waveform on the high-voltage electrode $v s$. time.

In all experiments, the amplitude of the high-voltage pulses and the time interval between them were selected to generate a spatially-distributed discharge in the whole domain between the electrodes without transitioning to an arc and without triggering combustion in the mixture. Figure 4 shows an example of waveform of the high-voltage pulses on the electrode. A sequence of two pulses was selected, with amplitudes on the high-voltage electrode $U=-50 \mathrm{kV}$ for the first one $(P 1)$ at all pressures and for all mixtures and $U=-30$ to $-46 \mathrm{kV}$ for the second one $(P 2)$ depending on the pressure and the mixture composition, and a $10-\mu$ s time interval between them. About $200 \mathrm{~mJ}$ was deposited to the gas mixture in two consecutive pulses, providing a specific deposited energy on the level of parts of $\mathrm{mJ}$ per $\mathrm{cm}^{-3}$ or 


\section{0 mbar $\mathrm{O}_{2}: \mathrm{CH}_{4}: \mathrm{Ar}^{\mathrm{H}} \mathrm{H}_{2}(7: 3: 8: 2)$}

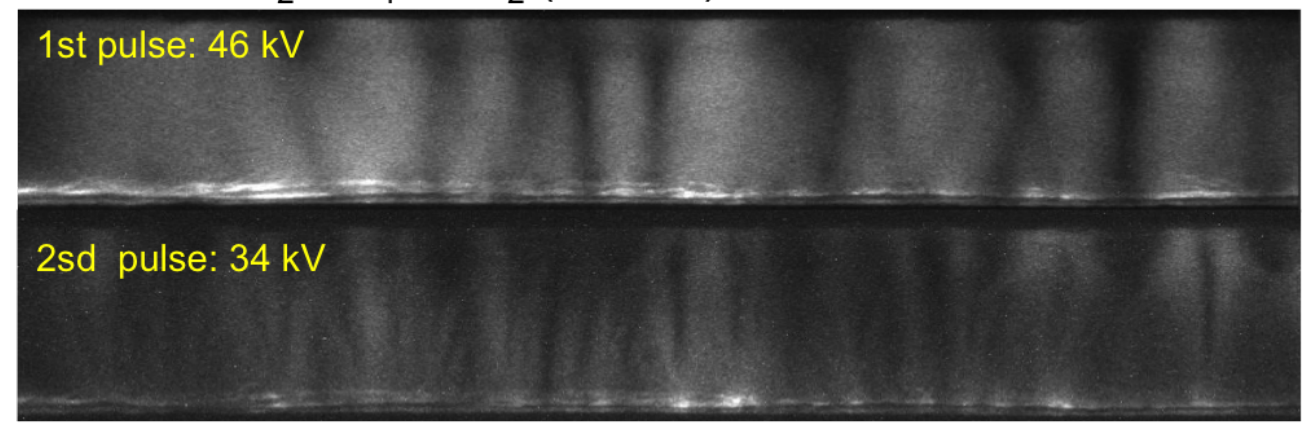

180 mbar $\mathrm{O}_{2}: \mathrm{CH}_{4}: \mathrm{Ar}_{2} \mathrm{H}_{2}(7: 3: 8: 2)$

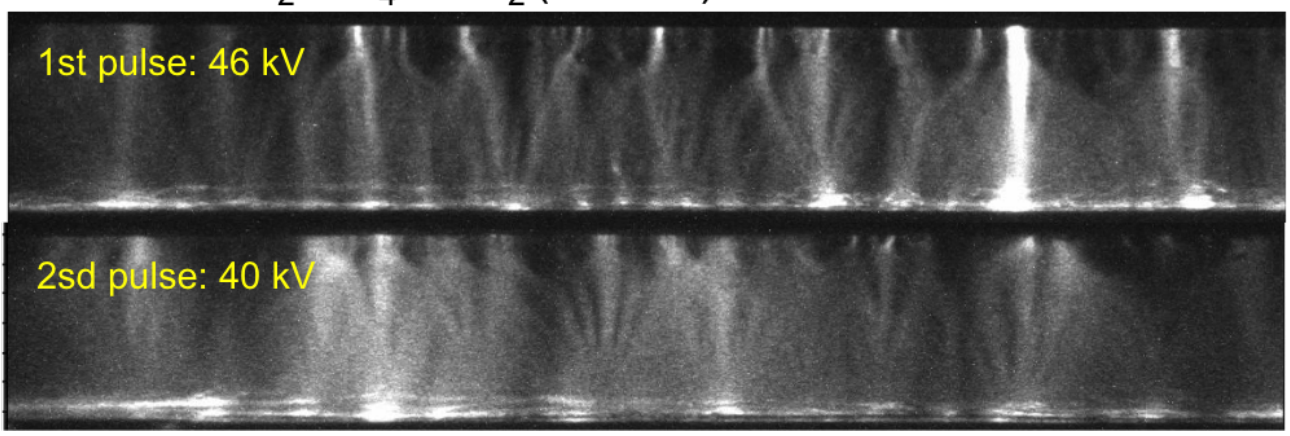

Fig. 5 ICCD images of the discharge ignited by the first high-voltage pulse, $P$, and the second high-voltage pulse, $P 2$, at 120 (top) and 180 (bottom) mbar in a $\mathrm{O}_{2}: \mathrm{CH}_{4}: \mathrm{Ar}: \mathrm{H}_{2}$ (7:3:8:2) mixture. The gate of the ICCD camera is $500 \mathrm{~ns}$.

$10^{-3} \mathrm{eV} /$ particle. At electric fields typical for nanosecond discharge, these values of specific delivered energy result in O-atom densities up to $1 \%$.

ICCD images of the discharge were first taken with a small depth of field $(5 \mathrm{~mm})$ and several focal distances in the direction perpendicular to the longitudinal axis of the discharge section in order to make sure that the discharge is volumetric and fills the central part of the section. Figure 5 shows ICCD images of the discharge integrated in time during the first and second pulses. In the $\mathrm{CH}_{4}: \mathrm{O}_{2}: \mathrm{Ar}_{\mathrm{H}} \mathrm{H}_{2}(10 \%)$ mixture at $120 \mathrm{mbar}$ and $180 \mathrm{mbar}$, the discharge resulted in a spatially-regular distribution of plasma. The plasma is homogeneous at 120 mbar for the first pulse and presented more concentrated spots for higher pressures such as $180 \mathrm{mbar}$. As a result, the pressure of 120 mbar was preferred for the experiments.

The discharge and the detonation wave were synchronized in time. The first discharge was triggered when the detonation wave arrived $5 \mathrm{~cm}$ above the beginning of the high-voltage electrode. Figures 6 show the detonation wave front (DWF) positions when pulses $P 1$ and $P 2$ were triggered. The detonation velocity measured at the chamber entry is $D=1938.1 \mathrm{~m} / \mathrm{s}$ (the Chapman-Jouguet value is $D_{C J}=1956 \mathrm{~m} / \mathrm{s}$ [13]). Taking into account the $10-\mu$ s time interval between $P 1$ and $P 2$, the detonation wave front (DWF) thus travels about $2 \mathrm{~cm}$ between the two pulses (Fig. 6).

Figure 7 shows typical soot recordings that compare detonation cells without (No Plasma, NP) and with the plasma action (With Plasma, WP). It can be seen that the detonation cell size is reduced through out the discharge zone called "plasma zone". For the NP case, the width $\lambda$ of the larger detonation cells is bounded by the distance $d$ between the chamber walls because of the relatively-low initial pressure, that is, $\lambda$ is equal to $d$. For the WP case, the recordings show that $\lambda$ has decreased by a factor about 2 in the plasma zone. Before and after the domain, outside of the plasma zone respectively, $\lambda$ is about equal to the same value $d$ as on the NP recordings.

It should be noted that the governing time scales of the discharge and the cell-size are different. Active species are produced in the discharge, that is, during $P 1$ and $P 2$ pulses ( $25 \mathrm{~ns} F W H M$ ), and in the near afterglow, up to the sub-microsecond time scale. The detonation wave passes the region initially occupied by nanosecond plasma during 
120 mbar $\mathrm{O}_{2}: \mathrm{CH}_{4}: \mathrm{Ar}: \mathrm{H}_{2}(7: 3: 8: 2)$

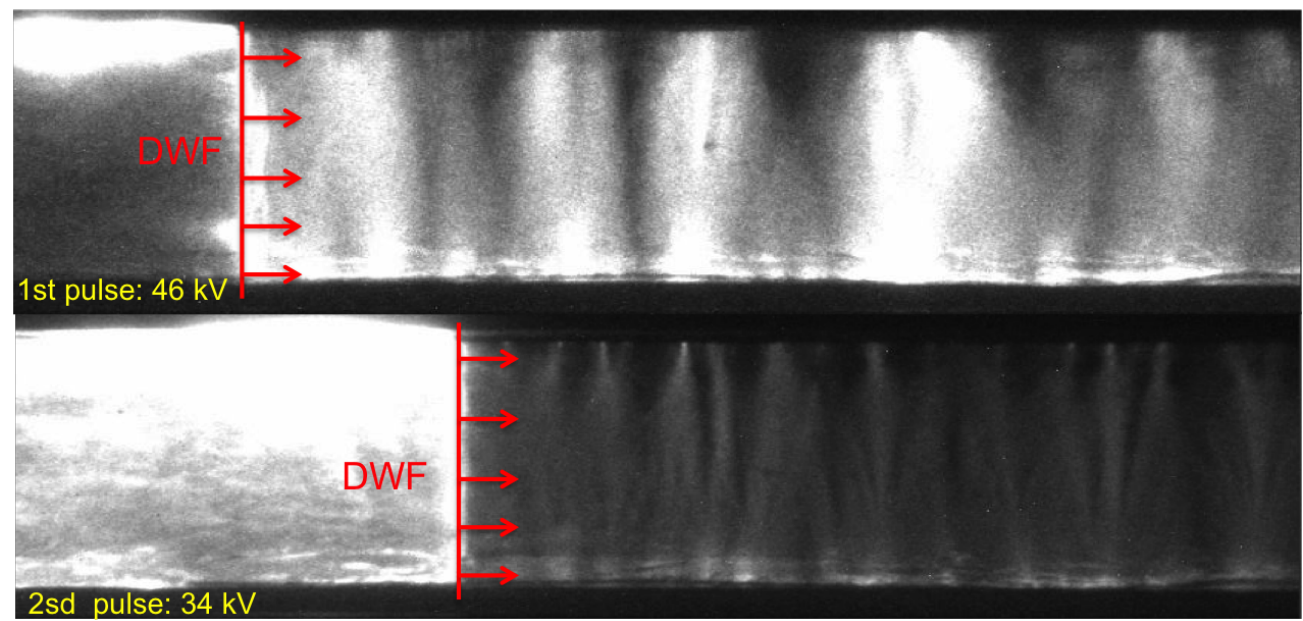

Fig. 6 ICCD images of the detonation wave front (DWF) and the discharge at the time corresponding to the initiation of the first discharge pulse $P 1$, time $t_{0}$ (top); the detonation wave and the discharge at the time corresponding to initiation of the second discharge pulse $P 2$, time $t_{0}+10 \mu$ s (bottom). The gate of the ICCD camera is $500 \mathrm{~ns}$.
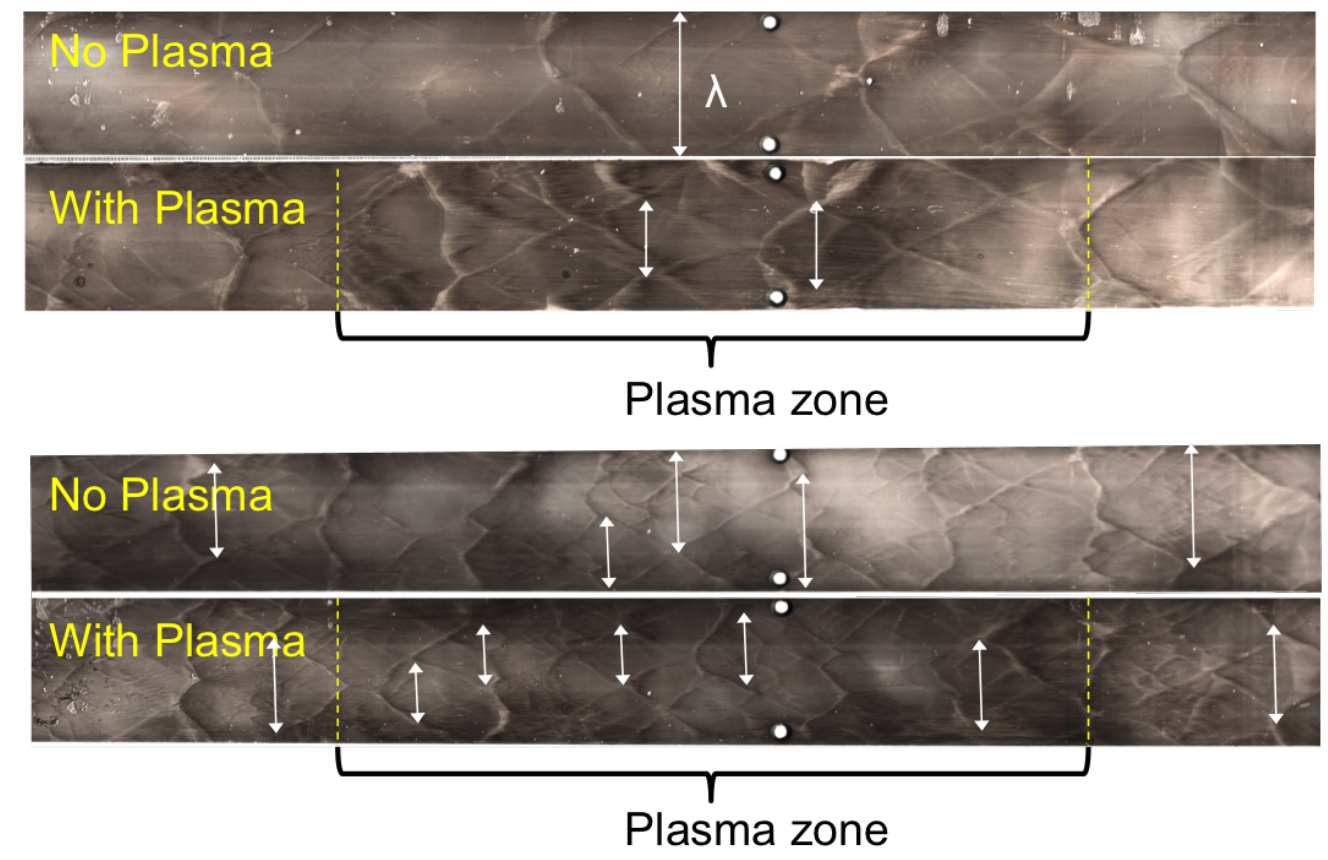

Fig. 7 Soot prints of the detonation wave without plasma and with plasma in the "plasma zone" domain at 120 mbar (top) and 180 mbar (bottom) for a $\mathrm{O}_{2}: \mathrm{CH}_{4}: \mathrm{Ar}_{2} \mathrm{H}_{2}$ (7:3:8:2) mixture. Typical sizes of the detonation cells are shown with white arrows.

hundreds of microseconds. A possible interpretation is that the radicals produced by the discharge, in particular oxygen atoms, shorten the mixture oxidation time at low pressure and temperature [14]. Plasma thus enhances mixture detonability by providing excited species that enhance reactions behind the detonation front. 


\section{Conclusion}

In the present work, volumetric nanosecond discharge is obtained in a $\mathrm{O}_{2}: \mathrm{CH}_{4}: \mathrm{Ar}: \mathrm{H}_{2}$ mixture at pressures ranging from 50 to 2000 mbar and ambient temperature in a $360 \times 50 \times 50-\mathrm{mm}^{3}$ volume ahead of the detonation front. The discharge was initiated by two consecutive pulses of 25-ns FWHM duration, and -50 and -30 to $-46-\mathrm{kV}$ amplitudes separated by $10 \mu \mathrm{s}$. The use of two pulses allows increasing production of deposited energy without transition to arc discharge. Decrease of detonation cell size by a factor of 2 at the optimal conditions determined in the study. It should be noted that the detonation wave passes the region initially occupied by nanosecond plasma during hundreds of microseconds. A suggested interpretation of the observed effect is that plasma triggers the mixture oxidation ahead of the detonation front.

\section{Acknowledgments}

This work is supported by the convention Ecole Polytechnique-DGA 2790 and by DGA financial support for the $\mathrm{PhD}$ Thesis of Mhedine Ali Cherif. The experiments were carried out at the Pprime institute in Poitiers. The authors wishes to thank Alain Claverie and Maxime Caron for their technical assistances. The electrode system was designed by Ali Majhoub and Jean-Carl Rousseau.

\section{References}

[1] Zhang, F., Shock Waves Science and Technology Library, Vol. 6: Detonation Dynamics, Vol. 6, Springer Science \& Business Media, 2012.

[2] Starikovskaia, S. M., "Plasma-assisted ignition and combustion: nanosecond discharges and development of kinetic mechanisms," Journal of Physics D: Applied Physics, Vol. 47, No. 35, 2014, p. 353001.

[3] Boulal, S., Vidal, P., and Zitoun, R., "Experimental investigation of detonation quenching in non-uniform compositions," Combustion and Flame, Vol. 172, 2016, pp. 222-233.

[4] Ju, Y., and Sun, W., "Plasma assisted combustion: Dynamics and chemistry," Progress in Energy and Combustion Science, Vol. 48, 2015, pp. 21-83.

[5] Starikovskiy, A., and Aleksandrov, N., "Plasma-assisted ignition and combustion," Progress in Energy and Combustion Science, Vol. 39, No. 1, 2013, pp. 61-110.

[6] Kosarev, I. N., Aleksandrov, N. L., Kindysheva, S. V., Starikovskaia, S. M., and Starikovskii, A. Y., "Kinetics of ignition of saturated hydrocarbons by nonequilibrium plasma: CH4-containing mixtures," Combustion and Flame, Vol. 154, No. 3, 2008, pp. 569-586.

[7] Zhukov, V. P., Rakitin, A. E., and Starikovskii, A. Y., "Effect of high-voltage pulsed discharges on deflagration to detonation transition," Journal of Propulsion and Power, Vol. 24, No. 1, 2008, pp. 88-93.

[8] Gray, J. A. T., and Lacoste, D. A., "Enhancement of the transition to detonation of a turbulent hydrogen-air flame by nanosecond repetitively pulsed plasma discharges," Combustion and Flame, Vol. 199, 2019, pp. 258-266.

[9] Tropina, A., Mahamud, R., Yorn, D. W., and Miles, R. B., "Deflagration to detonation transition assisted by equilibrium and non-equilibrium plasma," AIAA Aviation 2019 Forum, 2019, p. 3119.

[10] Crane, J., Shi, X., Singh, A. V., Tao, Y., and Wang, H., "Isolating the effect of induction length on detonation structure: Hydrogen-oxygen detonation promoted by ozone," Combustion and Flame, Vol. 200, 2019, pp. 44-52.

[11] Ali Cherif, M., Claverie, A., Vidal, P., Starikovskaia, S., and Shcherbanev, S., "Influence of moderate pressure nanosecond discharge on the structure of detonation wave," AIAA Scitech 2020 Forum, 2020, p. 1894.

[12] Lepikhin, N. D., Popov, N. A., and Starikovskaia, S. M., "Fast gas heating and radial distribution of active species in nanosecond capillary discharge in pure nitrogen and N2: O2 mixtures," Plasma Sources Science and Technology, Vol. 27, No. 5, 2018, p. 055005.

[13] Mc Bride, B., and Gordon, S., "NASA Computer Program for Calculation of Complex Chemical Equilibrium Compositions and Applications (CEA), https://www.grc.nasa.gov/WWW/CEAWeb/," NASA Reports 1311, Analysis (1994), and User's Manual and Program Description (1996), 1994.

[14] Bozhenkov, S. A., Starikovskaia, S. M., and Starikovskii, A. Y., "Nanosecond gas discharge ignition of H2- and CH4- containing mixtures," Combustion and flame, Vol. 133, No. 1-2, 2003, pp. 133-146. 